\title{
Premedication with low dose oral clonidine does not enhance postopera- tive analgesia of intrathecal morphine
}

Kelly V. Mayson MD FRCPC, Ed A. Gofton MD FRCPC, Keith G. Chambers MD MHSC

Purpose: A number of studies have demonstrated that perioperative intravenous, intrathecal, and epidural clonidine enhance postoperative analgesia. The results of previous studies on the usefulness of oral clonidine on enhancing postoperative analgesia have been mixed. The effect of a single preoperative dose of oral clonidine on postoperative analgesia was assessed in this study.

Methods: Forty-three male patients undergoing radical prostectomy were randomized to receive either 3 $\mu \mathrm{g} \cdot \mathrm{kg}^{-1}$ clonidine or placebo po $90 \mathrm{~min}$ prior to surgery. All patients received isobaric $15 \mathrm{mg}$ bupivacaine and intrathecal $5 \mu \mathrm{g} \cdot \mathrm{kg}^{-1}$ morphine, followed by a standardized general anesthetic, consisting of thiopental, sufentanil, rocuronium, isoflurane, oxygen and air. Postoperatively, PCA morphine use and visual analogue pain scores were recorded for the first $48 \mathrm{hr}$. The incidence and severity of side effects such as sedation, nausea, and pruritus were assessed, as well as patient satisfaction. Usage of PCA morphine was compared.

Results: There was no difference in total morphine requirements between the placebo and oral clonidine groups, nor in six hourly morphine usage $(P=0.96)$. Second, there was no difference in visual analogue pain scores, or the incidence of side effects. Patient satisfaction was high in both groups and again, no differences between groups was noted.

Conclusions: Oral clonidine $3 \mu \mathrm{g} \cdot \mathrm{kg}^{-1}$ as a premedication does not prolong the effect of intrathecal morphine: there was no difference in PCA morphine requirements $(P=0.96)$. Clonidine did not effect the incidence or severity of nausea or pruritus.

Objectif : Nombre d'études ont démontré que l'administration périopératoire, intraveineuse, intrathécale et péridurale de clonidine améliore l'analgésie postopératoire. Les études antérieures sur l'utilité de la clonidine orale en analgésie postopératoire ont donné des résultats variables. L'effet d'une dose préopératoire unique de clonidine orale sur l'analgésie postopératoire est évaluée dans la présente étude.

Méthode: Quarante-trois patients devant subir une prostatectomie radicale ont reçu, soit $3 \mu g^{\prime} \cdot \mathrm{kg}^{-1}$ de clonidine, soit un placebo po 90 min avant l'opération. Tous les patients ont reçu $15 \mathrm{mg}$ de bupivacaïne isobare et $5 \mu \mathrm{g} \cdot \mathrm{kg}^{-1}$ de morphine intrathécale suivis d'une anesthésie générale normale comprenant : thiopental, sufentanil, rocuronium, isoflurane, air et oxygène. Après l'opération, l'utilisation de morphine sous forme d'ACP et les scores de douleur à l'EVA ont été enregistrés pendant les 48 premières heures. L'incidence et la sévérité des effets secondaires, comme la sédation, les nausées, le prurit ont été évalués de même que la satisfaction du patient. L'utilisation de morphine ACP a été comparée.

Résultats : II n'y a pas eu de différence intergroupe quant à la consommation totale de morphine et à la l'utilisation horaire de morphine mesurée à six reprises $(P=0,96)$. De plus, il n'y a pas eu de différence de scores de douleur ou d'incidence d'effets secondaires. La satisfaction du patient était élevée dans les deux groupes, et encore une fois, sans différence intergroupe.

Conclusion : L'administration orale de $3 \mu \mathrm{g} \cdot \mathrm{kg}^{-1}$ de clonidine comme prémédication ne prolonge pas l'effet de la morphine intrathécale : il n'y a pas de différence de consommation de morphine en $\operatorname{ACP}(P=0,96)$. La clonidine ne modifie pas l'incidence ou la sévérité des nausées ou du prurit.

From the Vancouver General Hospital, University of British Columbia, Department of Anesthesia, Vancouver, B.C. Canada.

Address correspondence to: Dr. Kelly V. Mayson, Department of Anesthesia, LSP 2, Room 2449, 855 West 12th Avenue, Vancouver,

B.C., V5Z IM9 Canada. Phone: 604-875-4304; Fax: 604-875-5209; E-mail: kmayson@vanhosp.bc.ca

Accepted for publication April 16, 2000. 


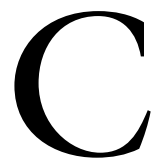

LONIDINE is a selective alpha-2 agonist, and has a variety of properties that are of potential benefit when used as premedication. It reduces sympathetic activity, and produces sedation and anxiolysis. It decreases anesthetic requirements of inhalation agents, intravenous agents such as propofol, and intraoperative opioids. ${ }^{1-, 3}$ It has been suggested that it may improve intraoperative cardiovascular stability by attenuating increases in blood pressure and heart rate, and may decrease myocardial ischemia. ${ }^{4}$ Oral clonidine also may be useful for premedication for regional anesthesia as it not only results in sedation, but it enhances and prolongs the effect of local anesthetic. ${ }^{5}$

Several studies found that perioperative intravenous, ${ }^{6}$ intrathecal, ${ }^{7}$ and epidural clonidine ${ }^{8,9,10}$ produce analgesia. The primary mechanism of clonidine analgesia is via a non-opioid, spinal action on - 2 receptors in the dorsal horn of the spinal cord. A few studies suggested that the use of oral clonidine may enhance postoperative analgesia but the results have been mixed. ${ }^{11-15}$ Other investigators have suggested that oral clonidine potentiates the effect of intrathecal morphine. ${ }^{16}$ Furthermore, there is speculation on the minimal effective dose of oral clonidine which enhances postoperative analgesia, ${ }^{11,13}$ as well as the minimal effective dose of clonidine which enhances spinal anesthesia. ${ }^{17}$

The objective of this study was to determine if a single preoperative dose of oral clonidine improved postoperative analgesia by decreasing morphine requirements in patients undergoing major abdominal surgery who received a single dose of intrathecal morphine.

\section{Methods}

The study was approved by the local ethics committee on human investigation and written, informed consent was obtained from each patient. This investigation was a prospective double-blind, placebo-controlled study. Male patients, ASA status I - III, scheduled to undergo radical prostatectomy were selected. Exclusion criteria included patients receiving preoperative clonidine or with a history of an adverse reaction to clonidine or morphine, patients with valvular heart disease, patients with a history of considerable alcohol use, and patients receiving medication with psychotrophic activity or chronic analgesic therapy. Fifty two male patients were enrolled in the study when assessed in our preadmission clinic, where the visual analogue pain scale, and the use of the PCA pump was explained. The patients were randomized by the hospital pharmacy by the use of a randomization table, to receive either $3 \mu \mathrm{g} \cdot \mathrm{kg}^{-1}$ clonidine or placebo (vitamin C) po, The study medication was administered 90 min preoperatively by the nursing staff in the same-day admission unit so that the anesthesiologist was blinded.

On arrival in the operating room, vital signs and sedation score were recorded, then an intravenous line was started and the patient was given a bolus of 500 $\mathrm{ml}$ Lactated Ringers solution. All patients received a spinal anesthetic at the level of the $\mathrm{L}_{2-3}$ or $\mathrm{L}_{3-4}$ intervertebral space with $15 \mathrm{mg}$ isobaric bupivacaine $(0.5 \%)$, and intrathecal $5 \mu \mathrm{g} \cdot \mathrm{kg}^{-1}$ morphine, followed by a standardized anesthetic induction consisting of $0.5 \mu \mathrm{g} \cdot \mathrm{kg}^{-1}$ sufentanil, $2-3 \mathrm{mg} \cdot \mathrm{kg}^{-1}$ thiopental until loss of consciousness, and $0.6 \mathrm{mg} \cdot \mathrm{kg}^{-1}$ rocuronium. Anesthesia was maintained with isoflurane, oxygen, and air, and 10-20 mg rocuronium as required for muscle relaxation. Hypotension, defined as a decrease in systolic blood pressure $>25 \%$ of the preoperative value was treated with $0.1 \mathrm{mg} \cdot \mathrm{kg}^{-1}$ ephedrine. Bradycardia (decrease in heart rate $>25 \%$ of preoperative value or a rate $<45 \mathrm{bpm}$ ) was treated with 0.1 $\mathrm{mg} \cdot \mathrm{kg}^{-1}$ atropine, The incidence of these hemodynamic intraoperative events was noted and the total dose of ephedrine was tabulated. At the end of surgery, the trachea was extubated as soon as possible after antagonism of the neuromuscular block with edrophonium and atropine.

In the postoperative recovery room, the patients were assessed by the nursing staff at frequent intervals for the occurrence of incisional pain. If pain was > VAS 4 , or the patient found the pain unacceptable they received $1-2 \mathrm{mg}$ morphine, every five minutes, until the PCA pump was started. The PCA settings were $1 \mathrm{mg} \cdot$ dose, lockout of eight minutes, with a four hourly maximum of $25 \mathrm{mg}$. The PCA morphine requirements were tabulated every six hours for $48 \mathrm{hr}$. The morphine received in the recovery room was included in the first PCA six hour requirement $(0-6$ hr). The intensity of pain was assessed using a visual analogue scale (VAS) $0-10(0=$ no pain, $10=$ worst pain imaginable) and was measured at the time of discharge from the postanesthetic care unit at rest, and every 12 $\mathrm{hr}$ for $48 \mathrm{hr}$ thereafter, at rest and with coughing by the nursing staff in the PACU and on the ward.

The duration and regression of spinal anesthesia was not directly assessed. The sensory level determined by sensation to ice, was determined on admission to the recovery room, as well as the duration of time to achieve the discharge criteria. Discharge criteria included: pain at a level acceptable to the patients, and/or visual analogue pain score $<5$, minimal nausea, sedation score $\leq 2$, ability to flex knees after a spinal anesthetic, blood pressure, and heart rate within normal limits for the patient, and respiratory rate of $8-24 \mathrm{bpm}$. 
TABLE I Patient demographics

\begin{tabular}{lll}
\hline & Placebo & Clonidine \\
\hline Number of patients & 19 & 24 \\
Age (yr) & $61.1 \pm 7$ & $62.3 \pm 5$ \\
ASA Status & 2 & 2 \\
Weight $(\mathrm{kg})$ & $80.5 \pm 9$ & $83.1 \pm 15$ \\
Height $(\mathrm{cm})$ & $176.5 \pm 10$ & $175.3 \pm 8$ \\
Duration of anesthesia $(\mathrm{min})$ & $160.6 \pm 20$ & $154.1 \pm 25$ \\
Duration in the PACU (min) & $181.2 \pm 106.5$ & $141.2 \pm 48.8$ \\
\hline
\end{tabular}

Values expressed as means \pm standard deviations

TABLE II Severity of postoperative side effects of preoperative oral clonidine and placebo. Scale $0=$ none, $1=$ mild, $2=$ moderate, $3=$ severe. Values given as median $\left(25-75^{\text {th }}\right.$ quantiles $)$

\begin{tabular}{ll}
\hline $\begin{array}{l}\text { Pruritus } \\
\text { Clonidine }\end{array}$ & $0(0-1)$ \\
Placebo & $1(0-1)$ \\
Nausea & $1(0-1)$ \\
Clonidine & $1(0-1)$ \\
Placebo & $0(0-1)$ \\
$\begin{array}{l}\text { Sedation } \\
\text { Clonidine }\end{array}$ & $0(0-0)$ \\
Placebo & \\
\hline
\end{tabular}

TABLE III Incidence of hypotension and bradycardia in clonidine $v s$ placebo groups

\begin{tabular}{llll}
\hline & Placebo & Clonidine & \\
\hline $\begin{array}{l}\text { Incidence of } \\
\text { hypotension (\%) }\end{array}$ & $13 / 19(68.4)$ & $18 / 24(75)$ & $\mathrm{P}=0.63$ \\
$\begin{array}{l}\text { Dose of ephedrine } \\
\text { (average) }\end{array}$ & $10 \pm 9.43 \mathrm{mg}$ & $18.81 \pm 17.97 \mathrm{mg}$ & $\mathrm{P}=0.5$ \\
$\begin{array}{l}\text { Incidence of } \\
\text { bradycardia (\%) }\end{array}$ & $2 / 19(10.5)$ & $2 / 24(8.3)$ & \\
\hline
\end{tabular}

Sedation, nausea, pruritus were recorded using a scale from 0 to 3 ( $0=$ none, $1=$ mild $2=$ moderate, $3=$ severe) and reassessed every $12 \mathrm{hr}$ by the nursing staff. On postoperative day three, the patients were asked to evaluate their degree of satisfaction with their postoperative pain management using a five-point Likert scale ( $1=$ very disappointing, $2=$ poor, $3=$ fair, $4=$ good, $5=$ excellent). In addition, the patients were also asked to evaluate the overall incidence and severity of side effects on same $0-3$ scale that the nursing staff used.

The study was designed to have a power of $80 \%$ to detect a 30\% reduction in morphine usage by enrolling approximately 20 patients per group. This was based on a literature review. ${ }^{12,14}$ PCA morphine usage was compared with a student $t$ test with $t=0.04$.

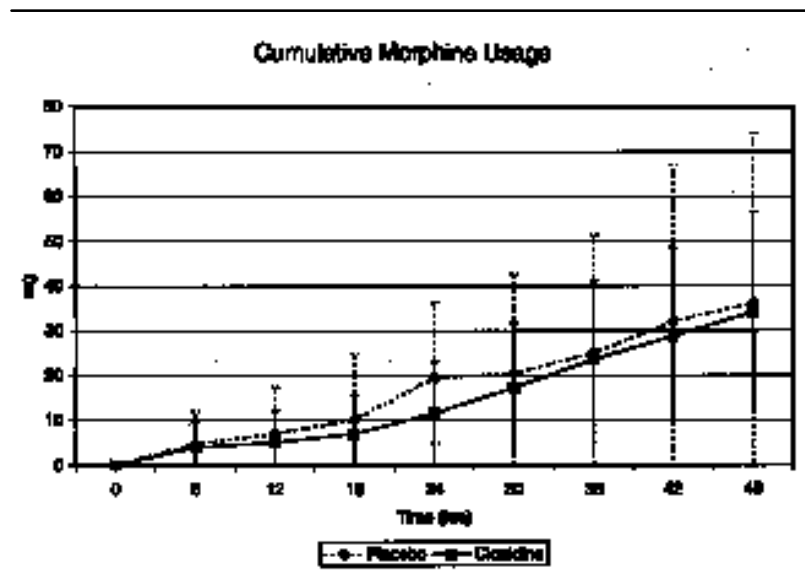

FIGURE 1 Cumulative postoperative PCA morphine requirements for each six hour period in both clonidine and control groups. Results are expressed as mean and standard deviation. $P=0.96$.

Patient demographics, duration of anesthesia, and time spent in the postoperative recovery room, VAS pain scores, incidence of bradycardia, severity of side effects, and patient satisfaction were compared with descriptive statistics.

The incidence of hypotension and the average dose of ephedrine per case were compared using a Chisquared test and Student's t test respectively.

Results

A total of 52 patients were enrolled in the preadmission clinic. Nine patients were excluded from the study, six patients did not receive the study protocol anesthetic, one had a different surgical procedure, in one patient spinal anesthesia was not technically possible, and one patient's PCA pump was erroneously discontinued after $24 \mathrm{hr}$. Patients were similar in age, weight and height and ASA status. Duration of anesthesia, and duration of time spent in the postoperative recovery room were also equivalent in both groups (Table I).

There was no difference in total morphine requirements between the control $(36.18 \mathrm{mg} \pm 38.01)$ and clonidine $(34.21 \mathrm{mg} \pm 22.34)$ groups, $(P=0.96)$, nor in six hourly morphine usage (Figure 1).

Visual analogue pain scores assessed at the time of discharge from the PACU (Postanesthetic Care Unit), and every $12 \mathrm{hr}$ postoperatively were not different between the two groups (Figures 2 and 3 ). Preoperative sedation did not differ between the two groups. Median scores for preoperative sedation $\left( \pm 25^{\text {th }}-75^{\text {th }}\right.$ quantiles $)$ were: control $0(0-1)$, and clonidine $0(0-1)$. 


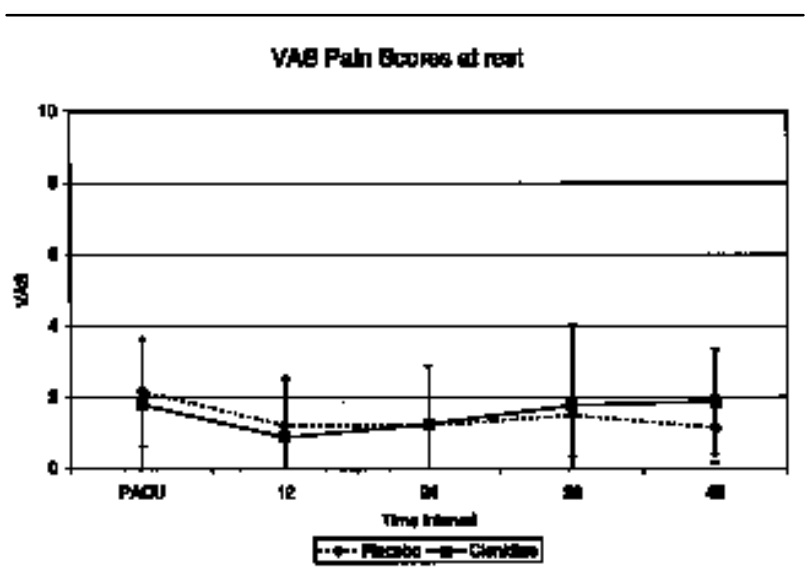

FIGURE 2 VAS for pain at rest in both groups at the time of discharge from the recovery room (PACU), and every $12 \mathrm{hr}$ for $48 \mathrm{hr}$ at rest. Results are expressed as mean and SD.

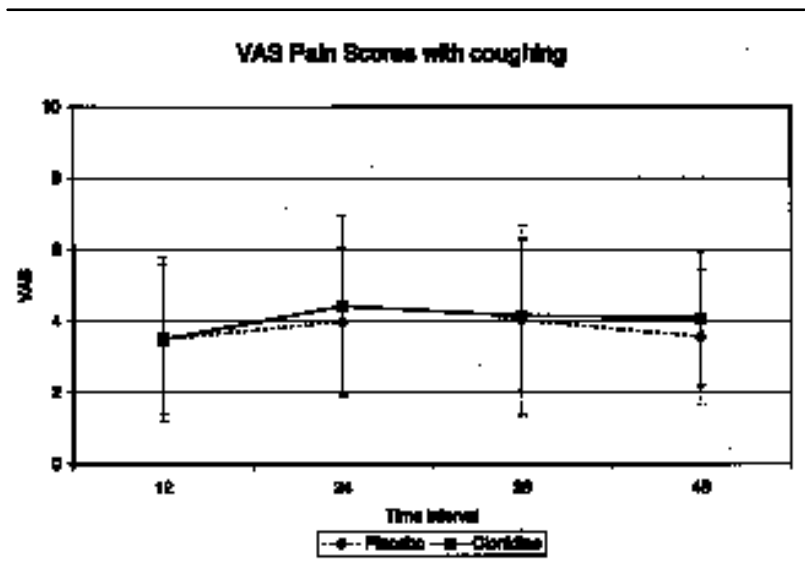

FIGURE 3 VAS for pain with coughing in both groups every 12 hr. Results are expressed as mean and SD.

The incidence of postoperative sedation, nausea, and pruritus was low and the data were pooled and median values $\left( \pm 25^{\text {th }}\right.$ to $75^{\text {th }}$ percentiles $)$ determined. The two groups did not differ (Table II). The median values $\left(25^{\text {th }}-75^{\text {th }}\right.$ quantiles $)$ of patient satisfaction with postoperative pain management was 5 (4-5) for placebo, and 4 (4-5) for clonidine treated patients. The response rate of completing the questionnaire was $81.4 \%(35 / 43)$.

Similar incidences of intraoperative hypotension and bradycardia were found in both groups. The apparently higher cumulative mean dose of ephedrine

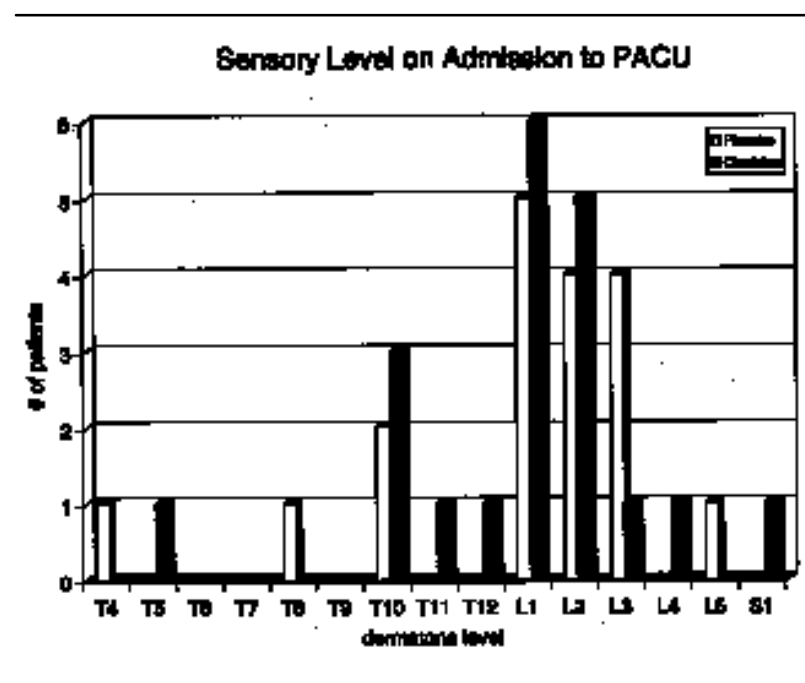

FIGURE 4 Distribution of sensory level of spinal anesthesia on admission to the postoperative anesthesia care unit.

required in the clonidine-treated group $18.81 \mathrm{mg} \pm$ 17.97 compared with control $10.0 \mathrm{mg} \pm 9.43 \mathrm{did}$ not achieve statistical significance $(P=0.5)$ (Table III).

The sensory level of anesthesia was assessed on arrival in the recovery room (Figure 4). The measurement was not performed on five patients (one in the control group, and four in the clonidine treated group).

\section{Discussion}

Previous studies on the usefulness of preoperative oral clonidine to reduce postoperative PCA morphine requirements have been mixed. ${ }^{11-15}$ Contrary to Goyashi et al., ${ }^{16}$ we were unable to demonstrate that oral clonidine prolongs the effect of intrathecal morphine: there was no difference in PCA morphine requirements. The use of a dose of $3 \mu \mathrm{g} \cdot \mathrm{kg}^{-1}$ clonidine po did not affect the incidence or severity of side effects such as nausea, pruiritus, or preoperative or postoperative sedation.

One criticism of this study is the use of a small dose of clonidine. Others have given a dose of $5 \mu \mathrm{g} \cdot \mathrm{kg}^{-1}$ clonidine po. ${ }^{12,16} \mathrm{~A}$ review of the literature demonstrated only two dose-response studies. Segal et al. ${ }^{11}$ had two treatment groups, a "low-dose" group which received two doses of $3 \mu \mathrm{g} \cdot \mathrm{kg}^{-1}$ clonidine $p o$, one on the night prior to surgery and one $90 \mathrm{~min}$ preoperatively, plus a transdermal clonidine patch, and a "highdose" group which received two doses of $6 \mu \mathrm{g} \cdot \mathrm{kg}^{-1}$ clonidine $p o$, plus the transdermal patch. Both doses of clonidine were equally effective in decreasing postoperative PCA morphine requirements. Mikawa et al. ${ }^{13}$ 
studied the effect of oral clonidine given preoperatively on postoperative pain in children undergoing minor surgery in a randomized, placebo-controlled study. The children received either placebo, $2 \mu \mathrm{g} \cdot \mathrm{kg}^{-1}$ clonidine, or $4 \mu \mathrm{g} \cdot \mathrm{kg}^{-1}$ clonidine. They found that 4 $\mu \mathrm{g} \cdot \mathrm{kg}^{-1}$ provided lower objective pain scores and resulted in reduced requirements for postoperative supplementary analgesics (diclofenac suppositories) than the other two regimens during the twelve hours after surgery.

A smaller dose of oral clonidine was chosen for our study because of reports of the effect of oral clonidine on the duration of spinal anesthesia. Ota et al. ${ }^{18}$ found that $150 \mu \mathrm{g}$ clonidine $p o$, given prior to tetracaine spinal anesthesia, prolonged the duration of sensory block. A follow-up study ${ }^{17}$ evaluated 75,150 , and 300 $\mu \mathrm{g}$ clonidine po given $60 \mathrm{~min}$ preoperatively. The prolongation of tetracaine was dose dependent and reached a maximal effect at $150 \mu \mathrm{g}\left(\sim 2.5 \mu \mathrm{g} \cdot \mathrm{kg}^{-1}\right)$. Furthermore, Singh et al. ${ }^{9}$ found that approximately $40 \%$ of patients that received $200 \mu \mathrm{g}$ clonidine po prior to tetracaine spinal anesthesia experienced episodes of bradycardia and hypotension, compared with only $10 \%$ of patients in the placebo group. Therefore, we felt that by choosing a dose of $3 \mu \mathrm{g} \cdot \mathrm{kg}^{-1}$ clonidine, we would achieve maximal effect of oral clonidine on spinal anesthesia and intrathecal morphine with the minimal effect on the cardiovascular system.

The exact mechanism of the interaction of oral clonidine and spinal anesthesia remains to be determined. We found a similar incidence of intraoperative hypotension and bradycardia in both groups The apparently higher cumulative dose of ephedrine required in the clonidine-treated group, did not reach statistical significance $(P=0.5)$.

The regression of spinal anesthesia was not directed measured. We only assessed the level of the sensory block on admission to the PACU and the duration of stay in PACU. The sensory levels did not differ between groups, nor did time to discharge from PACU (Table I).

Clonidine is rapidly and almost completely absorbed after oral administration, and reaches peak plasma concentrations within $60-90 \mathrm{~min}$. The oral preparation is an inexpensive medication and at the time that the study was undertaken it was the only available form of clonidine in Canada. It is highly lipid soluble and easily crosses the blood brain barrier and, therefore, may interact with alpha-adrenergic receptors at spinal and supraspinal sites within the central nervous system. We did not measure clonidine concentrations in the blood or cerebrospinal fluid. Studies using a combination of epidural clonidine and mor- phine $\mathrm{e}^{20-23}$ demonstrated improved postoperative analgesia, reflected by lower pain scores, and decreased need for supplemental analgesia. Co-administration of epidural morphine and clonidine $(75,150 \mu \mathrm{g})$ appears not only to potentiate but also to prolong the effect of epidural morphine. ${ }^{22,23}$ It was our hypothesis that the use of oral clonidine would result in a prolongation of the effect of intrathecal morphine. However, this study did not support the hypothesis. The only published study, by Goyagi et al. ${ }^{16}$, which showed a prolongation of the analgesia of intrathecal morphine by oral clonidine used $5 \mu \mathrm{g} \cdot \mathrm{kg}^{-1}$ and a smaller dose of intrathecal morphine $200 \mu \mathrm{g}\left(\sim 3.5 \mu \mathrm{g} \cdot \mathrm{kg}^{-1}\right)$ : no intraoperative opioids were given and all patients were female. We elected to use a lower dose of oral clonidine, $3 \mu \mathrm{g} \cdot \mathrm{kg}^{-1}$, and a higher dose of intrathecal morphine $\left(5 \mu \mathrm{g} \cdot \mathrm{kg}^{-1}\right)$, and all our patients were male. One needs to question whether this is due to the fact that this oral dose of clonidine does not produce concentrations of clonidine in the CSF to produce to analgesia. Also, one might wonder if gender differences in pharmacodynamic and pharmacokinetic behaviour that were suggested in a recent article on the emergence from propofol ${ }^{24}$ could contribute to the discrepancy in results between our study and that of Goyagi's et al. ${ }^{16}$

\section{Acknowledgments}

Our thanks to the nursing staff in the postanesthetic recovery room and the urology ward at Vancouver General for their assistance in the data collection, and to Janet Haines for her work on the Figures.

\section{References}

1 Bloor BC, Flacke WE. Reduction in halothane anesthetic requirement by clonidine, an alpha adrenergic agonist. Anesth Analg 1982; 61: 741-5.

2 Richards MJ, Skues MA, Jarvis AP, Prys-Roberts C Total i.v. anaesthetic with propofol and alfentanil: dose requirements for propofol and the effect of premedication with clonidine. Br J Anaesth 1990; 65: 157-63.

3 Ghignone M, Quinton L, Duke PC, Kehler CH, Calvillo $O$. Effects of clonidine on narcotic requirements and hemodynamic response during induction of fentanyl anesthesia and endotracheal intubation. Anesthesiology 1986; 64: 36-42.

4 Stühmeier K-D, Mainzer B, Cierpka J, Sandmann W, Tarnow J. Small, oral dose of clonidine reduces the incidence of intraoperative myocardial ischemia in patients having vascular surgery. Anesthesiology 1996; 85: 706-12.

5 Lui S, Chiu AA, Neal JM, Carpenter RL, Bainton BG, Gerancher JC. Oral clonidine prolongs lidocaine spinal 
anesthesia in human volunteers. Anesthesiology 1995; 82: 1353-9.

6 Bernard J-M, Hommeril J-L, Passuti N, Pinaud M. Postoperative analgesia by intravenous clonidine. Anesthesiology 1991; 75: 577-82.

7 Filos KS, Goudas LC, Patroni O, Polyzou V. Hemodynamic and analgesic profile after intrathecal clonidine in humans. A dose-response study. Anesthesiology 1994; 81: 591-601.

8 Eisenach J, Detweiller D, Hood D. Hemodynamic and analgesic actions of epidurally administered clonidine. Anesthesiology 1993; 78: 277-87.

9 Bernard J-M, Kick O, Bonnet F. Comparison of intravenous and epidural clonidine for postoperative patient-controlled analgesia. Anesth Analg 1995; 81: 706-12.

10 De Kock M, Wiederkher P, Laghimiche A, Scholtes J-L. Epidural clonidine used as the sole analgesic agent during and after abdominal surgery. A dose-response study. Anesthesiology 1997; 86: 285-92.

11 Segal IS, Jarvis DJ, Duncan SR, White PF, Maze M. Clinical efficacy of oral-transdermal clonidine combinations during the perioperative period. Anesthesiology 1991; 74: 220-5.

12 Park J, Forrest J, Kolesar R, Bhola D, Beattie S, Chu C Oral clonidine reduces postoperative PCA morphine requirements. Can J Anaesth 1996; 43: 900-6.

13 Mikawa K, Nishina K, Maekawa N, Obara H. Oral clonidine premedication reduces postoperative pain in children. Anesth Analg 1996; 82: 225-30.

14 Benhamou D, Narchi P, Hamza J, Marx M, Peyrol $M-T$, Sembeil F. Addition of oral clonidine to postoperative patient-controlled analgesia with i.v. morphine. $\mathrm{Br} \mathrm{J}$ Anaesth 1994; 72: 537-40.

15 Ellis JE, Drijuers G, Pedlow S, et al. Premedication with oral and transdermal clonidine provides safe and efficacious postoperative sympatholysis. Anesth Analg 1994;79: 1133-40.

16 Goyagi T, Nishikawa T. Oral clonidine premedication enhances the quality of postoperative analgesia by intrathecal morphine. Anesth Analg 1996; 82: 1192-6.

17 Ota K, Namiki A, Iwasaki H, Takahashi I. Dose-related prolongation of tetracaine spinal anesthesia by oral clonidine in humans. Anesth Analg 1994; 79: 1121-5.

18 Ota K, Namiki A, Ujike $\Upsilon$, Takahashi I. Prolongation of tetracaine spinal anesthesia by oral clonidine. Anesth Analg 1992; 75: 262-4.

19 Singh H, Lui J, Gaines GY, White PF. Effect of oral clonidine and intrathecal fentanyl on tetracaine spinal block. Anesth Analg 1994; 79: 1113-6.

20 Motsch J, Gräber E, Ludwig K Addition of clonidine enhances postoperative analgesia from epidural morphine: a double-blind study. Anesthesiology 1990; 73: 1067-73.
21 Mogensen T, Eliasen K, Ejlersen E, Vegger P, Nielsen IK, Kehlet $H$ Epidural clonidine enhances postoperative analgesia from a combined low-dose epidural bupivacaine and morphine regimen. Anesth Analg 1992; 75: 607-10.

22 Anzai $\Upsilon$, Niskikawa T. Thoracic epidural clonidine and morphine for postoperative pain relief. Can J Anaesth 1995; 42: 292-7.

23 Capogna G, Celleno D, Zangrillo A, Costantino P, Foresta $S$. Addition of clonidine to epidural morphine enhances postoperative analgesia after Cesarean delivery. Reg Anesth 1995; 20: 57-61.

24 Gan T, Glass P, Sigl J, et al. Women emerge from general anesthesia with propofol/alfentanil/nitrous oxide faster than men. Anesthesiology 1999; 90: 1283-7. 